\title{
Natural History of Menopause Symptoms in Primary Care Patients: A MetroNet Study
}

\author{
Jinping Xu, MD, MS, Monina Bartoces, PhD, Anne Victoria Neale, PhD, MPH, \\ Rhonda K. Dailey, MD Justin Northrup, MPT, and Kendra L. Schwartz, MD, MSPH
}

Background: The association between changes in menopausal status and menopause-related symptom reporting over the course of the menopause transition is not well understood, especially whether there are any racial differences in this association.

Objective: To determine (1) the prevalence and the natural history of menopause symptoms among primary care patients approaching, or at menopause; (2) the relationship between self-reported symptoms and menopausal status; and (3) whether this relationship varies in African American and white women.

Study Design: Cross-sectional self-report survey of 342 women aged 40 to 55 years (31.6\% African American) were recruited from 8 family practice centers in 2000 and 2001.

Results: Among 251 women without surgical menopause, $133(53.0 \%)$ were premenopausal, 72 (28.7\%) were peri-menopausal, and $46(18.3 \%)$ were postmenopausal. The most commonly reported symptoms were joint/muscle pain and headache, which did not vary by menopausal status. As many as $28.6 \%$ of the women with regular menstruation reported hot flashes, and $18.8 \%$ had night sweats; although both symptoms were strongly associated with changes in menopausal status $(P<.01)$. During the natural menopausal transition, white women had increasing trends of nervousness, memory loss, vaginal dryness, loss of sexual interest, hot flashes, and night sweats while African American women only had increasing trend of painful sex and hot flashes. In multivariate analyses, loss of sexual interest was associated with postmenopause status in white but not in African American women.

Conclusions: Symptoms are not uncommon among premenopausal women and become more prevalent as the transition through menopause occurs. The prevalence of vasomotor symptoms in premenopausal women may be an under-recognized aspect of the natural history of the menopause transition. African American and white women may present different symptoms through menopause transition. (J Am Board Fam Pract 2005;18:374-82.)

Menopause marks the end of reproductive capacity of women and results from the permanent cessation of ovarian function. Natural menopause is a gradual process that occurs for most women between the ages of 47 and 55 years. ${ }^{1}$ It is confirmed by absence of menstrual periods for 12 consecutive months, excluding other obvious pathologic or physiologic causes. ${ }^{2}$

Submitted, revised, 30 March 2005.

From the Division of Practice-Based Research, Department of Family Medicine, Wayne State University, Detroit, Michigan.

Funding: This study was funded by a Research Stimulation Award (to AVN) from the American Academy of Family Physicians Foundation (Grant G0009RS).

Corresponding author: Anne Victoria Neale, PhD, MPH, Department of Family Medicine, Wayne State University, 101 E. Alexandrine, Room 241, Detroit, MI 48201-2153 (e-mail: vneale@med.wayne.edu).

This paper was presented at Michigan Family Practice Research Day XXVII, East Lansing, Michigan, 6 May 2004.

MetroNet is a metropolitan Detroit practice-based research network.
The peri-menopause, a time of changing ovarian function, precedes the final menses by 2 to 8 years (median of 3.8 years). ${ }^{3}$ The clinical manifestations of this transition to menopause are not well understood; however, some symptoms such as hot flashes, begin in the peri-menopause ${ }^{1}$ and increase as women progress through the menopause. ${ }^{4}$ Nonspecific somatic and psychological symptoms, including tiredness, irritability, insomnia, palpitations, memory or concentration difficulties, and mood swings or depression have been commonly reported. ${ }^{5}$

However, the prevalence of symptoms differ widely and their relationship with the menopause transition varies. ${ }^{6,7}$ In addition, the specific symptoms associated with menopause vary among cultures, ${ }^{8}$ race/ethnicity, ${ }^{9}$ social groups, ${ }^{10}$ and persons. ${ }^{11}$ In a population-based study, white women reported psychosomatic symptoms more frequently whereas vasomotor symptoms were more common in African-American women. ${ }^{12}$ 
Few studies have examined menopause symptomatology in different ethnic groups, especially in primary care settings. To optimize the health care for middle-aged women, we need to understand the process by which women describe, explain, and experience menopause and also to understand the factors that may shape their experiences.

Here we describe self-reported menopausal symptoms among racially diverse women at midlife with natural menopause (ie, without surgery), according to their menopausal status. The primary objectives of this study were to determine: (1) the prevalence of self-reported menopause-related symptoms among women presenting to primary care clinics at various stages of the natural menopausal transition; (2) the relationship between symptoms and menopausal status; and (3) whether the relationship varies in African American and white women.

\section{Methods}

\section{Subject Recruitment}

The data were collected from January 2000 through February 2001. Consecutive women between 40 and 55 years of age were recruited into this cross-sectional study as they presented for primary care at 8 family medicine centers (FMCs) in Michigan. At $6 \mathrm{FMCs}$, the front desk staff asked age-eligible female patients to complete the voluntary and anonymous self-administered survey of menopause symptoms when they checked in for their appointment. In 2 FMCs, a research assistant was used to recruit patients. The 8 FMCs serve a diverse population, with 3 centers located in urban settings, 3 in suburban Detroit, and 2 in rural Michigan. Five of the FMCs are residency training centers, and 3 are nonteaching group practices.

\section{Data Collection}

The research protocol was approved by the Human Investigation Committee at Wayne State University. The study questionnaire included 17 common menopause symptoms based on the Greene Climacteric Scale. ${ }^{13}$ In our survey instrument, these symptoms were not labeled as menopause-related; rather they were presented as "a list of symptoms that women your age might experience." Women were asked to check any symptoms that they experienced within the past 6 months. They were also asked to report demographic items (age, race, ed- ucation), menstrual history (menstrual status, history of hysterectomy and oophorectomy, hormone replacement therapy use, oral contraceptive pill use), current health conditions, and smoking status. We also asked about the use of herbal products for menopause symptom relief, and these results are reported elsewhere. ${ }^{14}$

\section{Data Analysis}

To determine how symptoms progressed through the menopause transition, we made descriptive comparisons contrasting premenopausal, perimenopausal, and postmenopausal women. The operational definition of menopause status is as follows: premenopause was defined by having regular menstrual periods in the previous 12 months; perimenopause as having no period in the previous 3 months, but at least one menstruation in the previous 12 months; and postmenopause as having no period in the previous 12 months. $\chi^{2}$ test, Fisher's exact test, or ANOVA, were used whenever appropriate. A multivariate analysis using a logistic regression model was also performed (SAS 9.1).

To determine whether our grouping of symptoms from a primary care sample were comparable with that of the population-based Study of Women's Health Across the Nation (SWAN), a multiethnic, multisite study of 14,906 women aged 40 to 55 years, ${ }^{12}$ we performed a factor analysis on the same symptoms. Because there were 3 categories of menopausal status, polytomous regression was used. Women in postmenopausal and perimenopausal status were compared with those at premenopausal. Each symptom was coded as either "present" or "absent."

Because several studies have indicated that African American and white women may report different symptoms at menopause, $, 9,12$ we performed separate regression analyses for these 2 ethnic groups. Potential confounders of the association between symptoms and menopausal status were evaluated in multivariate analyses using a forward selection procedure, retaining those variables that changed the symptom estimates by at least $10 \%$. Because age, hormone replacement therapy, and smoking were found to be predictors in other studies, ${ }^{15,16}$ these variables were included in all models, irrespective of their significance as confounders in this study. Other variables assessed as potential confounders were education status ( $\leq$ high school, some college/ college graduate, graduate degree), medical condi- 
tions (none, 1 to $3, \geq 4$ ), and current medications (none, 1 to $3, \geq 4$ ).

\section{Results}

\section{Characteristics of the Study Sample}

Overall, 462 consecutive women between 40 and 55 years of age were invited to participate, and 425 (92\%) were enrolled and filled out the questionnaire. Of these, 71 (16.7\%) women were excluded because of unknown status of surgical history (hysterectomy or oophorectomy), and 12 women were excluded because of extensive missing symptoms data (Figure 1).

Table 1 shows the characteristics of the study sample $(n=342)$ by menopause status. The mean age of all the participants was 46.6 years $(\mathrm{SD}=$ 4.3). Women averaged 2.8 visits $(\mathrm{SD}=2.5)$ to their physician in the previous 6 months. Almost one third of the sample self-identified as African American $(31.6 \%), 30.2 \%$ were smokers, and $70 \%$ had some college education. Just over half $(52.3 \%)$ were recruited from the suburban FPCs, with the remaining divided between the urban FPCs, and the rural FPCs. The most prevalent self-reported medical conditions were hypertension (22.6\%), muscle and joint pain $(12.6 \%)$, thyroid disease $(11.7 \%)$, allergies $(9.9 \%)$, and depression $(9.9 \%)$. The medications most frequently used were for hypertension $(22.6 \%)$, pain $(15.2 \%)$, depression $(13.5 \%)$, hormone therapy (18.2\%), and thyroid dysfunction (11.4\%).

Ninety one of $342(26.6 \%)$ women reported surgical menopause (either hysterectomy and/or oophorectomy) and thus were excluded from the analyses of symptomatology, leaving 251 women: 133 (53.0\%) were premenopausal; 72 (28.7\%) were perimenopausal, and $46(18.3 \%)$ were postmenopausal (Table 1).

Among the postmenopause group, the mean age at natural menopause was 47.0 years $(\mathrm{SD}=4.3$ ) and the median age was 48 years. The majority of postmenopausal women $(57.9 \%)$ were within the first 3 years of menopause (mean 3.7, SD $=2.9$, median 3.0). Age was significantly associated with menopause status $(P<.001)$. Race was not associated with age at menopause $(P=.69)$.

Premenopausal women were significantly younger, had fewer comorbidities, and took fewer medications than perimenopausal and postmenopausal women (see Table 1). One third of post-

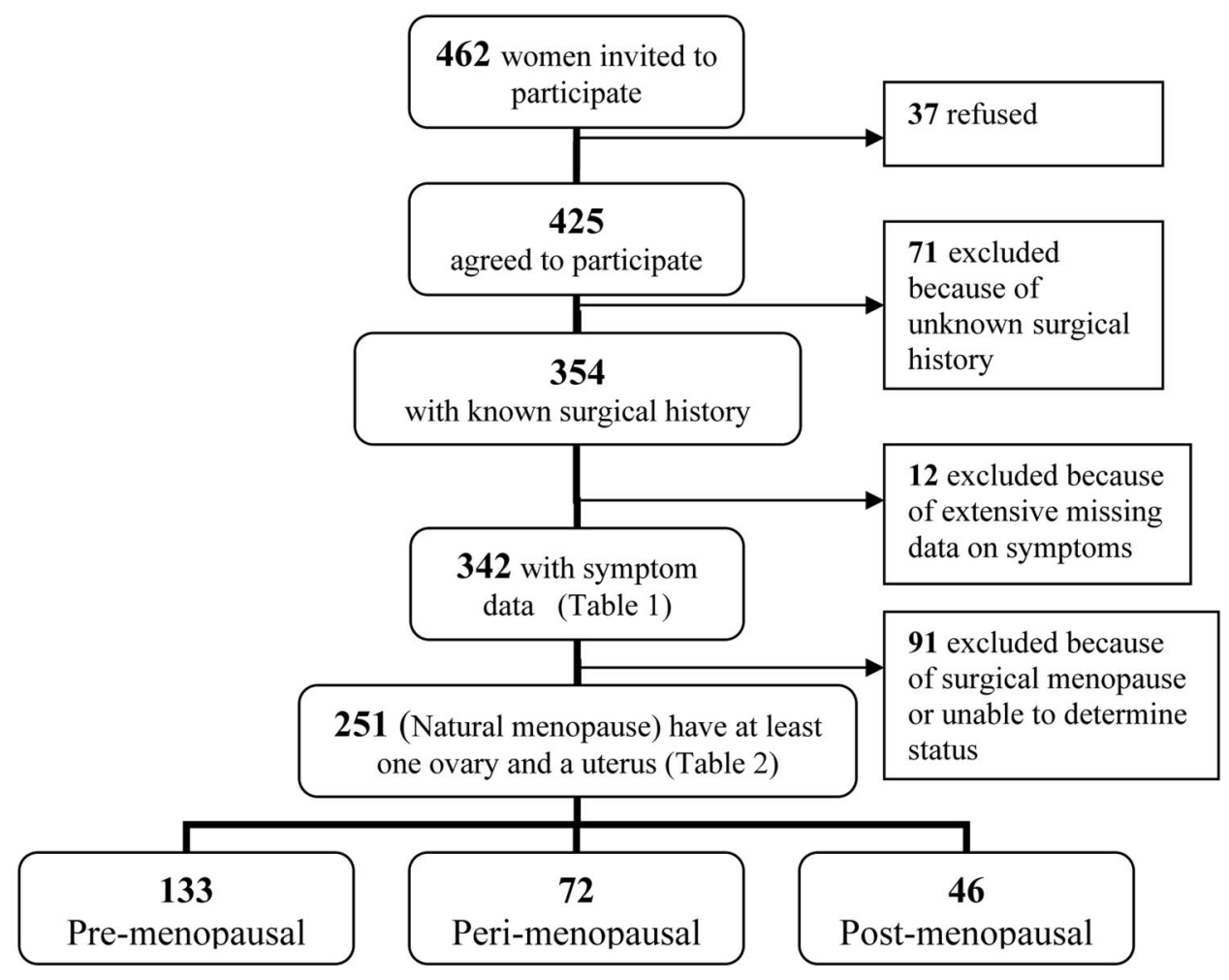

Figure 1. Flow Diagram of the Study Participants. 
Table 1. Demographic and Health Characteristics by Menopausal Status of Women in Family Practice Centers (Michigan, 2000-2001).

\begin{tabular}{|c|c|c|c|c|c|c|c|c|c|c|c|}
\hline \multirow{3}{*}{$\begin{array}{l}\text { Demographic } \\
\text { Characteristics }\end{array}$} & & & \multicolumn{9}{|c|}{ Menopausal Status } \\
\hline & \multicolumn{2}{|c|}{ All $(\mathrm{N}=342)$} & \multicolumn{2}{|c|}{ Pre $(N=133)$} & \multicolumn{2}{|c|}{ Peri $(\mathrm{N}=72)$} & \multicolumn{2}{|c|}{ Post $(\mathrm{N}=46)$} & \multicolumn{2}{|c|}{$\begin{array}{l}\text { Surgical } \\
(\mathrm{N}=91)\end{array}$} & \multirow[b]{2}{*}{$P$ Value } \\
\hline & $N$ & $(\%)$ & $N$ & $(\%)$ & $N$ & $(\%)$ & $N$ & $(\%)$ & $N$ & $(\%)$ & \\
\hline \multicolumn{12}{|l|}{ Race } \\
\hline White & 216 & $(65.1)$ & 96 & $(73.8)$ & 44 & $(62.0)$ & 27 & $(58.7)$ & 49 & $(57.6)$ & \multirow[t]{4}{*}{$<.0001$} \\
\hline African American & 105 & (31.6) & 30 & (23.1) & 24 & $(33.8)$ & 16 & $(34.8)$ & 35 & $(41.2)$ & \\
\hline Other & 11 & $(3.3)$ & 4 & $(3.1)$ & 3 & $(4.2)$ & 3 & $(6.5)$ & 1 & (1.2) & \\
\hline Missing & 10 & & & & & & & & & & \\
\hline \multicolumn{12}{|l|}{ Education } \\
\hline$\leq$ High school & 101 & $(30.0)$ & 36 & $(27.7)$ & 20 & $(28.2)$ & 14 & $(30.4)$ & 31 & $(34.4)$ & \multirow[t]{4}{*}{.228} \\
\hline $\begin{array}{l}\text { Some college/college } \\
\text { graduate }\end{array}$ & 197 & $(58.4)$ & 74 & $(56.9)$ & 48 & $(67.6)$ & 28 & $(60.9)$ & 47 & $(52.2)$ & \\
\hline Graduate degree & 39 & $(11.6)$ & 20 & $(15.4)$ & 3 & $(4.2)$ & 4 & $(8.7)$ & 12 & $(13.3)$ & \\
\hline Missing & 5 & & & & & & & & & & \\
\hline \multicolumn{12}{|l|}{ Practice location } \\
\hline Urban & 81 & $(23.7)$ & 20 & $(15.0)$ & 21 & $(29.2)$ & 11 & $(23.9)$ & 29 & (31.9) & \multirow[t]{3}{*}{.043} \\
\hline Suburban & 179 & $(52.3)$ & 75 & $(56.4)$ & 36 & $(50.0)$ & 28 & $(60.9)$ & 40 & $(44.0)$ & \\
\hline Rural & 82 & $(24.0)$ & 38 & $(28.6)$ & 15 & $(20.8)$ & 7 & $(15.2)$ & 22 & $(24.2)$ & \\
\hline \multicolumn{12}{|l|}{ Current smoking } \\
\hline Yes & 101 & $(30.2)$ & 32 & $(24.8)$ & 21 & $(30.4)$ & 18 & $(39.1)$ & 30 & $(33.3)$ & \multirow[t]{3}{*}{.268} \\
\hline No & 233 & $(69.8)$ & 97 & $(75.2)$ & 48 & $(69.6)$ & 28 & $(60.9)$ & 60 & $(66.7)$ & \\
\hline Missing & 8 & & & & & & & & & & \\
\hline \multicolumn{12}{|l|}{ Hormone therapy use } \\
\hline Yes & 67 & (21.4) & 5 & $(4.2)$ & 6 & $(9.2)$ & 15 & $(34.9)$ & 41 & $(47.7)$ & \multirow[t]{3}{*}{$<.0001$} \\
\hline No & 246 & (78.6) & 114 & (95.8) & 59 & (90.8) & 28 & $(65.1)$ & 45 & $(52.3)$ & \\
\hline Missing & 29 & & & & & & & & & & \\
\hline \multicolumn{12}{|l|}{ Medical conditions } \\
\hline None & 120 & $(35.1)$ & 52 & $(39.1)$ & 29 & $(40.3)$ & 14 & $(30.4)$ & 25 & $(27.5)$ & \multirow[t]{3}{*}{.017} \\
\hline $1-3$ & 166 & $(48.5)$ & 69 & $(51.9)$ & 33 & $(45.8)$ & 23 & $(50.0)$ & 41 & $(45.1)$ & \\
\hline$\geq 4$ & 56 & $(16.4)$ & 12 & $(9.0)$ & 10 & $(13.9)$ & 9 & $(19.6)$ & 25 & $(27.5)$ & \\
\hline \multicolumn{12}{|l|}{ Current medications } \\
\hline None & 114 & $(33.3)$ & 49 & $(36.8)$ & 29 & $(40.3)$ & 13 & $(28.3)$ & 23 & $(25.3)$ & \multirow[t]{3}{*}{.026} \\
\hline $1-3$ & 165 & $(48.2)$ & 69 & $(51.9)$ & 29 & $(40.3)$ & 25 & $(54.3)$ & 42 & $(46.2)$ & \\
\hline \multirow[t]{2}{*}{$\geq 4$} & 63 & (18.4) & 15 & $(11.3)$ & 14 & (19.4) & 8 & (17.4) & 26 & (28.6) & \\
\hline & Mean & $(\mathrm{SD})$ & Mean & $(\mathrm{SD})$ & Mean & (SD) & Mean & (SD) & Mean & $(\mathrm{SD})$ & \\
\hline Age & 46.6 & $(4.3)$ & 44.6 & $(3.3)$ & 46.6 & $(4.3)$ & 50.5 & (3.4) & 47.7 & $(4.3)$ & $<.0001$ \\
\hline Doctor visits & 2.8 & $(2.5)$ & 2.8 & (3.1) & 2.6 & (1.7) & 2.4 & (1.3) & 3.3 & $(2.5)$ & 0.151 \\
\hline Missing & 19 & & & & & & & & & & \\
\hline
\end{tabular}

menopausal women were currently taking hormone replacement therapy (HRT), compared with less than $10 \%$ of women in the premenopausal and perimenopausal groups $(P<.001)$. (Note that these data were collected before subsequent reports of the adverse health outcomes of HRT. ${ }^{17}$ )

\section{Factor Analyses by Race/Ethnicity, and Comparison with a Population-Based Study}

The results of the factor analysis performed on 10 symptoms investigated in a previous populationbased study (SWAN) ${ }^{12}$ for African American and white women are shown in Table 2. When the number of factors was not specified, 2 factors were extracted from data on white women and 3 from
African American women. For white women, factor 1 included joint/muscle pain, headache, irritability, depression/sadness, memory loss, fast heartbeat, and nervousness; factor 2 included hot flashes/ flushes, night sweats, and vaginal dryness. For African American women, factor 1 included joint/ muscle pain, headache, memory loss, and fast heartbeat; factor 2 included hot flashes, night sweats and vaginal dryness; and factor 3 included irritability, depression/sadness, and nervousness. When the number of factors was specified $(n=2)$ for African American women, the 2 factor loadings were remarkably similar to those of white women (Table 2), except for one symptom, irritability, which seemed to load similarly in both factors. 
Table 2. Comparison of Results of Factor Analysis between Our Study and the Study of Women's Health Across the Nation (SWAN).

\begin{tabular}{|c|c|c|c|c|c|c|c|c|}
\hline \multirow[b]{3}{*}{ Symptoms } & \multicolumn{4}{|c|}{ Our Study } & \multicolumn{4}{|c|}{ SWAN* } \\
\hline & \multicolumn{2}{|c|}{ White } & \multicolumn{2}{|c|}{ African American } & \multicolumn{2}{|c|}{ White } & \multicolumn{2}{|c|}{ African American } \\
\hline & Factor I & Factor II & Factor I & Factor II & Factor I & Factor II & Factor I & Factor II \\
\hline Nervousness & 0.74 & -0.07 & 0.65 & 0.01 & 0.73 & 0.05 & 0.75 & 0.11 \\
\hline Fast heartbeat ${ }^{\dagger}$ & 0.48 & 0.04 & 0.59 & 0.17 & 0.40 & 0.32 & 0.44 & 0.26 \\
\hline Depression/sadness & 0.53 & 0.03 & 0.70 & -0.05 & 0.67 & 0.10 & 0.73 & 0.07 \\
\hline Memory loss ${ }^{\dagger}$ & 0.47 & 0.16 & 0.58 & -0.02 & 0.48 & 0.25 & 0.50 & 0.30 \\
\hline Headache & 0.31 & 0.09 & 0.49 & -0.03 & 0.51 & 0.06 & 0.48 & 0.09 \\
\hline Joint/muscle pain ${ }^{\dagger}$ & 0.29 & 0.15 & 0.51 & -0.06 & 0.45 & 0.20 & 0.45 & 0.28 \\
\hline Irritability & 0.61 & 0.10 & 0.35 & 0.40 & 0.67 & 0.03 & 0.70 & 0.05 \\
\hline Night sweats & 0.05 & 0.62 & 0.00 & 0.70 & 0.06 & 0.82 & 0.11 & 0.81 \\
\hline Vaginal dryness & -0.01 & 0.52 & -0.20 & 0.71 & 0.16 & 0.36 & 0.19 & 0.45 \\
\hline Hot flashes/flushes & 0.16 & 0.43 & 0.24 & 0.58 & 0.04 & 0.83 & 0.08 & 0.83 \\
\hline
\end{tabular}

*Data extracted from the article by Avis et al. ${ }^{12}$

${ }^{\dagger}$ These symptoms were labeled as heart pounding, forgetfulness and stiffness, respectively, in SWAN.

\section{Menopausal Status, Race/Ethnicity, and Menopause Symptoms}

The most prevalent symptoms reported by all women were joint/muscle pain $(57 \%)$, and headache $(54.7 \%)$, which were not associated with menopause status. Other common symptoms including irritability $(46.4 \%)$ and difficulty sleeping (45.6\%), which is borderline associated with menopause status (Table 3). Among white women, the most prevalent symptoms were headache, joint/ muscle pain, and irritability at premenopause; joint/muscle pain, irritability and difficulty sleeping at perimenopause; and hot flashes/flushes, joint/ muscle pain, and irritability at postmenopause. Among African Americans, the most prevalent symptoms were joint/muscle pain and headache at premenopause; joint/muscle pain, night sweats and hot flashes at perimenopause; and hot flashes, headache, and difficulty sleeping at postmenopause. Trend analysis indicated that among white women, the prevalence of symptoms of nervousness, memory loss, vaginal dryness, loss of sexual interest, hot flashes/flushes, and night sweats increased with menopausal transition $(P<.05)$. However, among African Americans, only symptoms of painful sex and hot flashes/flushes showed an increasing linear trend $(P<.05)$ (Table 3). The mean number of reported symptoms was also associated with menopausal status $(P<.001)$. Premenopausal women reported an average of 4.5 (SD 3.8) symptoms compared with 7.1 (SD 4.3) symptoms reported by perimenopausal women, and 6.6 (SD 4.7) reported by postmenopausal women (data not shown).

As expected, compared with regularly menstruating women, those in perimenopause and postmenopause were most likely to report vasomotor symptoms (hot flashes, night sweats, vaginal dryness, and painful sex $)(P<.01$ for all comparisons). However, a substantial number of premenopausal women reported vasomotor symptoms such as hot flashes (28.6\%), and night sweats (18.2\%) (Table 3).

Table 4 shows the unadjusted odds ratios and $95 \%$ confidence intervals for symptoms by race and menopausal status. Among white women, those who had symptoms of memory loss, loss of sexual interest, hot flashes, and night sweats were more likely to be in the perimenopausal and postmenopausal status; those who reported symptoms of nervousness, irritability, and difficulty sleeping were more likely to be in the perimenopausal status; and those who experienced vaginal dryness were more likely to be postmenopausal. Among African American women, those who had symptoms of irritability, memory loss, weakness/fatigue, hot flashes, night sweats, and fast heartbeat were more likely to be in the perimenopausal status, and those with painful sex were more likely to be postmenopausal.

In multivariate analyses, loss of sexual interest was associated with postmenopause $(\mathrm{OR}=2.03$; $95 \% \mathrm{CI}=1.05-3.90 ; P=.034)$ and borderline associated with perimenopause $(\mathrm{OR}=1.56 ; 95 \%$ 


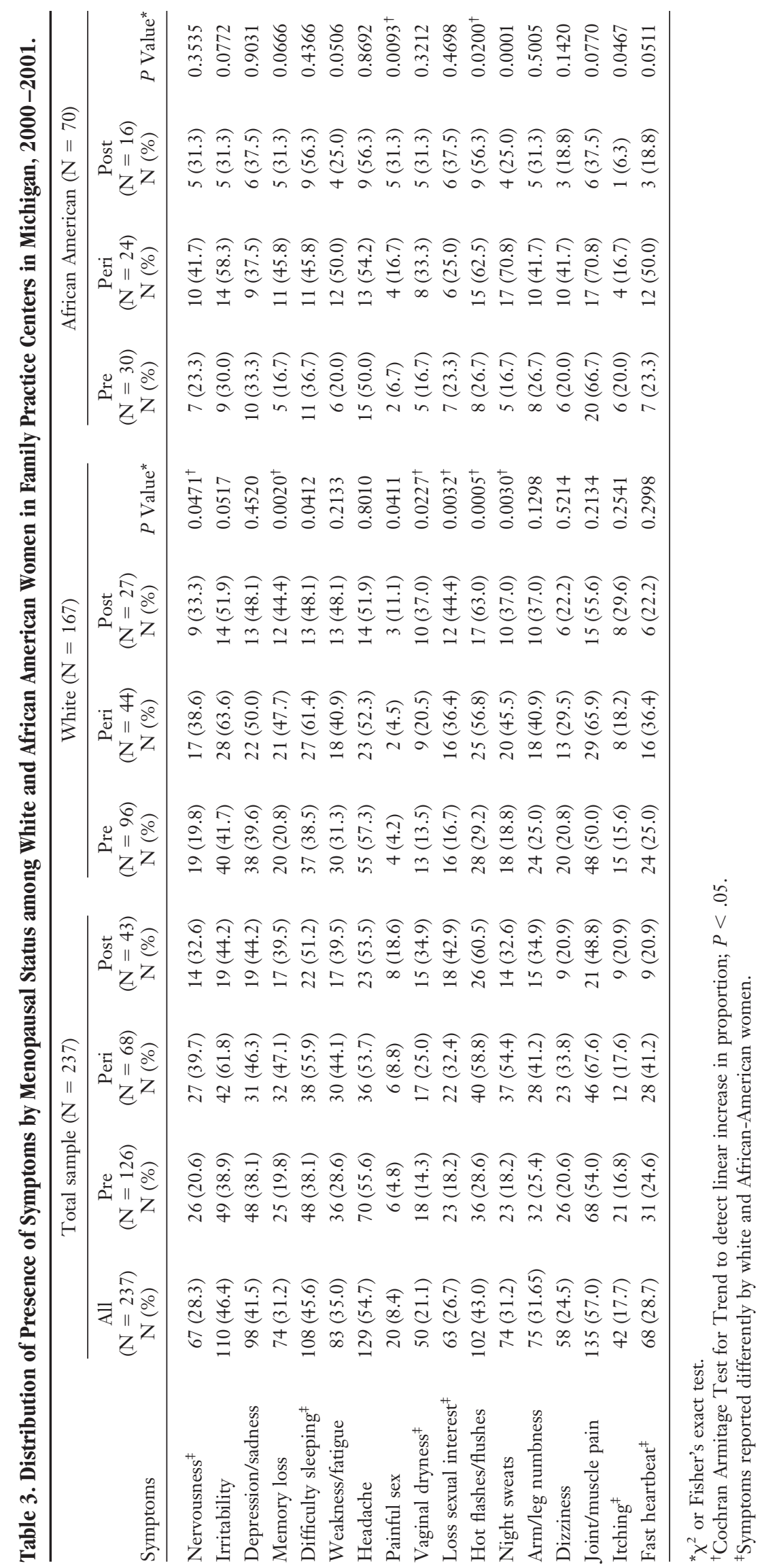


Table 4. Unadjusted OR and 95\% CI for Symptoms by Menopausal Status among White and African American Women in Family Practice Centers in Michigan, 2000-2001.

\begin{tabular}{|c|c|c|c|c|c|c|c|c|}
\hline \multirow[b]{4}{*}{ Symptoms* } & \multicolumn{8}{|c|}{ Menopausal Status ${ }^{\dagger}$} \\
\hline & \multicolumn{4}{|c|}{ White $(\mathrm{N}=167)$} & \multicolumn{4}{|c|}{ African American $(\mathrm{N}=70)$} \\
\hline & \multicolumn{2}{|c|}{ Perimenopausal } & \multicolumn{2}{|c|}{ Postmenopausal } & \multicolumn{2}{|c|}{ Perimenopausal } & \multicolumn{2}{|c|}{ Postmenopausal } \\
\hline & OR & $95 \% \mathrm{CI}$ & OR & $95 \% \mathrm{CI}$ & OR & $95 \% \mathrm{CI}$ & OR & $95 \% \mathrm{CI}$ \\
\hline Nervousness & 1.59 & $1.08-2.37^{\ddagger}$ & 1.42 & $0.89-2.28$ & 1.53 & $0.85-2.75$ & 1.22 & $0.62-2.41$ \\
\hline Irritability & 1.57 & $1.08-2.26^{\ddagger}$ & 1.23 & $0.80-1.88$ & 1.81 & $1.03-3.17^{\ddagger}$ & 1.03 & $0.53-1.99$ \\
\hline Depression/sadness & 1.24 & $0.86-1.77$ & 1.19 & $0.77-1.83$ & 1.13 & $0.64-1.99$ & 1.09 & $0.58-2.06$ \\
\hline Memory loss & 1.86 & $1.27-2.74^{\ddagger}$ & 1.74 & $1.11-2.74^{\ddagger}$ & 2.06 & $1.10-3.85^{\ddagger}$ & 1.51 & $0.74-3.08$ \\
\hline Difficulty sleeping & 1.59 & $1.10-2.95^{\ddagger}$ & 1.22 & $0.79-1.87$ & 1.21 & $0.70-2.09$ & 1.49 & $0.80-2.76$ \\
\hline Weakness/fatigue & 1.23 & $0.85-1.79$ & 1.43 & $0.93-2.21$ & 2.00 & $1.10-3.64^{\ddagger}$ & 1.15 & $0.56-2.37$ \\
\hline Headache & 0.90 & $0.63-1.29$ & 0.90 & $0.58-1.29$ & 1.14 & $0.66-1.97$ & 1.13 & $0.62-2.09$ \\
\hline Painful sex & 0.96 & $0.40-2.28$ & 1.69 & $0.78-3.70$ & 1.67 & $0.68-4.10$ & 2.52 & $1.03-6.15^{\dagger}$ \\
\hline Vaginal dryness & 1.28 & $0.80-2.05$ & 1.94 & $1.19-3.16^{\ddagger}$ & 1.58 & $0.83-3.00$ & 1.51 & $0.74-3.08$ \\
\hline Loss sexual interest & 1.72 & $1.14-2.59^{\ddagger}$ & 2.00 & $1.26-3.18^{\ddagger}$ & 1.05 & $0.56-1.96$ & 1.48 & $0.76-2.89$ \\
\hline Hot flashes/flushes & 1.79 & $1.23-2.59^{\ddagger}$ & 2.03 & $1.30-3.18^{\ddagger}$ & 2.14 & $1.20-3.82^{\ddagger}$ & 1.88 & $0.99-3.56$ \\
\hline Night sweats & 1.90 & $1.28-2.81^{\ddagger}$ & 1.60 & $1.00-2.55$ & 3.48 & $1.82-6.68^{\ddagger}$ & 1.29 & $0.61-2.71$ \\
\hline Arm/leg numbness & 1.44 & $0.99-2.11$ & 1.32 & $0.84-2.09$ & 1.40 & $0.79-2.49$ & 1.12 & $0.57-2.17$ \\
\hline Dizziness & 1.26 & $0.84-1.90$ & 1.04 & $0.62-1.75$ & 1.69 & $0.92-3.09$ & 0.96 & $0.44-2.08$ \\
\hline Joint/muscle pain & 1.39 & $0.96-2.01$ & 1.12 & $0.73-1.72$ & 1.10 & $0.62-1.97$ & 0.55 & $0.29-1.03$ \\
\hline Itching & 1.09 & $0.68-1.76$ & 1.51 & $0.92-2.48$ & 0.89 & $0.44-1.80$ & 0.52 & $0.17-1.56$ \\
\hline Fast heartbeat & 1.31 & $0.89-1.92$ & 0.93 & $0.56-1.54$ & 1.81 & $1.01-3.25^{\ddagger}$ & 0.87 & $0.41-1.86$ \\
\hline
\end{tabular}

*Coded 'absent' or 'present'; reference is 'absent'.

${ }^{\dagger}$ Reference is pre-menopausal.

${ }^{\ddagger}$ Significant, $P<.05$

CI $=0.98-2.49 ; P=.063)$ among white women. This association was adjusted for age, smoking status, hormone replacement therapy, and memory loss. Among African American women, the symptom of night sweats was associated with perimenopause $(\mathrm{OR}=4.05 ; 95 \% \mathrm{CI}=1.31-12.55 ; P=$ .0154) but not with postmenopause after controlling for confounders (age, smoking, hot flashes, fast heartbeat, painful sex, and memory loss). There were only 5 African American women who were on hormone replacement therapy, so this variable was not controlled in this model. However, when we did a sub-analysis excluding women who had hormone replacement therapy, night sweats was only slightly associated with perimenopausal status $(\mathrm{OR}=2.89 ; 95 \% \mathrm{CI}=0.91-9.22 ; P=.0724)$, adjusting for the same confounders from the previous model.

\section{Discussion}

We examined the natural history of symptoms associated with menopause reported by African American and white women at midlife recruited from 8 diverse primary care practices. Perhaps the most surprising finding was the unexpectedly high reports of vasomotor symptoms among women still experiencing regular menstruation. Vasomotor symptoms, such as hot flashes, are known to be associated with variable and lower estrogen levels as women go through the menopause. ${ }^{1}$ Although our data indicate an increased trend for hot flashes in both African American and white women as they progress through the stages of menopause, the decreased estrogen theory fails to explain why some regularly menstruating women experience hot flashes or why hot flashes are not experienced by all perimenopausal or postmenopausal women. ${ }^{18} \mathrm{Few}$ studies have investigated hot flashes in older reproductive women when menstrual cycles are still regular, but there are at least 2 other reports of vasomotor symptoms in premenopausal women. Hahn et $\mathrm{al}^{18}$ reported that menopause-like hot flashes were common in reproductive women, particularly those with premenstrual syndrome (PMS) or menstrual cycle-related symptoms in a sample recruited from a PMS clinic. Freeman et $\mathrm{a}^{19}$ found that $31 \%$ 
of a population-based sample of women aged 35 to 47 who were regularly menstruating reported hot flashes, which is similar to what we found in this study.

The results of the factor analyses of selected symptoms investigated in a previous populationbased study identified 2 factors with similar loadings for both African American and white women. ${ }^{12}$ Similarly, 2 factors were evident in our data for both African American and white women, with one factor composed of vasomotor symptoms, and another factor made up of a combination of psychosomatic and psychological symptoms. These comparable results indicate that these selected symptoms may be reliable measures of menstrual symptomatology in population-based as well as clinic-based studies.

Avis et $\mathrm{al}^{12}$ reporting on the SWAN study, found that white American women have more psychosomatic symptoms than other racial/ethnic groups and that African American women report more vasomotor symptoms, after controlling for age, education, health, and economic strain. Our study showed that African American women reported significantly more painful sex but did not report more hot flashes, night sweats, or vaginal dryness than whites. Among white women, loss of sexual interest was the only symptom that remained a significant predictor of postmenopause after adjusting for age, smoking status, hormone replacement therapy, and memory loss. Among African American women, night sweats was the only symptom that remained a significant predictor of perimenopause after controlling for age, smoking status, hot flashes, fast heartbeat, painful sex, and memory loss.

We observed a younger age at menopause in our clinic-based group of women (mean 47, median 48) than in many other studies. There is no obvious explanation for this difference. But we found that there are at least 2 other reports of similar age at menopause. ${ }^{20,21}$ Our study relied on recalled age at menopause, and some misclassification is expected. The data on menopause in this study were collected with a self-administered questionnaire, but the questions used to assess age at menopause are similar to those used in other studies.

The study has both strengths and limitations. The data were collected by self-report and we did not verify menopause status with blood hormone level testing. However, the use of standard symp- tom questions makes it feasible to compare our findings with other studies. Although the questionnaire asked about symptom severity, the large amount of missing data on severity made it impractical to quantify the severity of each individual symptom. Our study used a sample of women recruited from primary care settings, and they might have had more health problems, life stresses, and a higher incidence of psychological morbidity than women in the general population. ${ }^{12}$ However, our findings should be more representative of the patients that primary care clinicians see in their daily practice. The comparability of our loadings on symptom factors with those of the much larger population-based study ${ }^{12}$ provides confidence that our clinic-based sample may be generalizable to the larger population.

Menopause can be a challenging stage of life. Hot flashes are associated with a decreased quality of life, ${ }^{22}$ and are a primary reason that midlife women seek medical care. ${ }^{23}$ Most of the menopause-associated symptoms that we studied were nonspecific and could be attributed to other medical and/or mental conditions or medications. Primary care providers must consider other factors/ problems as well as menopause in their differential diagnosis. For example, Mold et $\mathrm{al}^{24}$ found that night sweats reported by primary care patients were associated with panic attacks, greater body mass index, chronic infection, sleep disturbances, antihistamines, and antidepressants, in addition to menopause.

Women who seek treatment for menopauserelated symptoms such as hot flashes may be more anxious and less able to cope with stress than women who don't seek treatment. ${ }^{25}$ Hardy and $\mathrm{Kuh}^{4}$ have suggested that work and family stresses may influence symptom reporting during the menopause transition. Others suggest that an increase in psychological symptoms may be associated with current life events and difficulties, particularly those experienced in family life, which often take place concurrently with the menopausal transition. ${ }^{4,26}$ To provide appropriate advice and support to their patients, primary care providers should recognize that many symptoms associated with menopause, including hot flashes, may begin in the pre-menopause years, and for some women, they may be indicative of other psychosocial or medical issues. It may also be helpful for clinicians to be aware that African American and white 
women may present with different symptoms during menopause.

\section{References}

1. Greendale GA, Lee NP, Arriola ER. The menopause. Lancet 1999;353:571-80.

2. Notelovitz M. Is routine use of estrogen indicated in postmenopausal women? An opposing view. J Fam Pract 1989;29:410-5.

3. McKinlay SM, Brambilla DJ, Posner JG. The normal menopause transition. Maturitas 1992;14:10315.

4. Hardy R, Kuh D. Change in psychological and vasomotor symptom reporting during the menopause. Soc Sci Med 2002;55:1975-88.

5. Kenemans P. Menopause, HRT and menopausal symptoms. J Epidemiol Biostat 1999;4:141-6.

6. Klein P, Versi E, Herzog A. Mood and the menopause. Br J Obstet Gynaecol 1999;106:1-4.

7. Nicol-Smith L. Causality, menopause, and depression: a critical review of the literature. BMJ 1996; 313:1229-32.

8. Lock M. Menopause in cultural context. Exp Gerontol. 1994:29:307-17.

9. Gold EB, Sternfeld B, Kelsey JL, et al. Relation of demographic and lifestyle factors to symptoms in a multiracial/ethnic population of women $40-55$ years of age. Am J Epidemiol 2000;152:463-73.

10. Kuh DL, Wadsworth M, Hardy R. Women's health in midlife: the influence of the menopause, social factors and health in earlier life. Br J Obstet Gynaecol 1997;104:923-33.

11. Choi MW. The menopausal transition: change, loss, and adaptation. Holist Nurs Pract 1995;9:53-62.

12. Avis NE, Stellato R, Crawford S, et al. Is there a menopausal syndrome? Menopausal status and symptoms across racial/ethnic groups. Soc Sci Med 2001;52:345-56.

13. Greene JG. Constructing a standard climacteric scale. Maturitas 1998;29:25-31.

14. Dailey RK, Neale AV, Northrup J, West P, Schwartz KL. Herbal product use and menopause symptom relief in primary care patients: a MetroNet study. J Womens Health (Larchmt) 2003;12:633-41.

15. Midgette AS, Baron JA. Cigarette smoking and the risk of natural menopause. Epidemiology 1990;1:47480.

16. MacMahon B, Worcester J. Age at menopause. United States-1960-1962. Vital Health Stat 1 1966; 11:1-20.

17. Rossouw JE, Anderson GL, Prentice RL, et al. Risks and benefits of estrogen plus progestin in healthy postmenopausal women: principal results from the Women's Health Initiative randomized controlled trial. JAMA 2002;288:321-33.

18. Hahn PM, Wong J, Reid RL. Menopausal-like hot flashes reported in women of reproductive age. Fertil Steril 1998;70:913-8.

19. Freeman EW, Sammel MD, Grisso JA, Battistini M, Garcia-Espagna B, Hollander L. Hot flashes in the late reproductive years: risk factors for African American and Caucasian women. J Womens Health Gend Based Med 2001;10:67-76.

20. Cooper GS, Sandler DP. Age at natural menopause and mortality. Ann Epidemiol 1998;8:229-35.

21. Fuh J-L, Wang S-J, Lu S-R, Juang K-D, Chiu LM. The kinmen women-health investigation (KIWI): a menopausal study of a population aged 40-54. Maturitas 2001;39:117-24.

22. Groeneveld FP, Bareman FP, Barentsen R, Dokter HJ, Drogendijk AC, Hoes AW. Vasomotor symptoms and well-being in the climacteric years. Maturitas 1996;23:293-9.

23. Anderson E, Hamburger S, Liu JH, Rebar RW. Characteristics of menopausal women seeking assistance. Am J Obstet Gynecol. 1987;156:428-33.

24. Mold JW, Mathew MK, Belgore S, DeHaven M. Prevalence of night sweats in primary care patients: an OKPRN and TAFP- Net collaborative study. J Fam Pract. 2002;51:452-6.

25. Hunter MS, Liao KL. Determinants of treatment choice for menopausal hot flushes: hormonal versus psychological versus no treatment. J Psychosom Obstet Gynaecol 1995;16:101-8.

26. Kaufert PA, Gilbert P, Tate R. The Manitoba Project: a re-examination of the link between menopause and depression. Maturitas 1992;14:143-55. 